\title{
Article
}

\section{The Prevalence of Use of Various Post-Exercise Recovery Methods after Training among Elite Endurance Athletes}

\author{
Eduard Bezuglov $1,2,3,4 \oplus$, Artemii Lazarev ${ }^{2}$, Vladimir Khaitin ${ }^{5,6} \oplus^{\infty}$, Sergey Chegin ${ }^{7}$, Aleksandra Tikhonova ${ }^{2}(\mathbb{D}$, \\ Oleg Talibov ${ }^{8}$, Dagmara Gerasimuk ${ }^{9}$ and Zbigniew Waśkiewicz ${ }^{1,9, *} \mathbb{C}$
}

1 Department of Sports Medicine and Medical Rehabilitation, Sechenov First Moscow State Medical University (Sechenov University), 119435 Moscow, Russia; e.n.bezuglov@gmail.com

2 High Performance Sport Laboratory, Moscow Witte University, 115432 Moscow, Russia; lazarevartemii1@gmail.com (A.L.); sandratikho@gmail.com (A.T.)

3 Sirius University of Science and Technology, 354349 Sochi, Russia

4 Federal Research and Clinical Center of Sports Medicine and Rehabilitation of Federal Medical Biological Agency, 121059 Moscow, Russia

5 Department of Sports Medicine and Medical Rehabilitation, Pavlov First State Medical University, 197022 Saint-Petersburg, Russia; khaitinvladimir@gmail.com

6 Football Club Zenit, 197341 Saint-Petersburg, Russia

7 Olympic Reserve Sport School, 430032 Saransk, Russia; info@smartrecovery.su

8 Department of Internal Medicine, Clinical Pharmacology and Emergency Medicine, Moscow State University of Medicine and Dentistry, 127006 Moscow, Russia; oleg.talibov@gmail.com

check for updates

Citation: Bezuglov, E.; Lazarev, A.; Khaitin, V.; Chegin, S.; Tikhonova, A.; Talibov, O.; Gerasimuk, D.; Waśkiewicz, Z. The Prevalence of Use of Various Post-Exercise Recovery Methods after Training among Elite Endurance Athletes. Int. J. Environ. Res. Public Health 2021, 18, 11698. https://doi.org/10.3390/ ijerph182111698

Academic Editor: Corrado Lupo

Received: 14 October 2021

Accepted: 1 November 2021

Published: 7 November 2021

Publisher's Note: MDPI stays neutral with regard to jurisdictional claims in published maps and institutional affiliations.

Copyright: (c) 2021 by the authors Licensee MDPI, Basel, Switzerland. This article is an open access article distributed under the terms and conditions of the Creative Commons Attribution (CC BY) license (https:/ / creativecommons.org/licenses/by/ $4.0 /)$.
9 Institute of Sport Science, Jerzy Kukuczka Academy of Physical Education, 40-065 Katowice, Poland; d.gerasimuk@awf.katowice.pl

* Correspondence: z.waskiewicz@awf.katowice.pl

\begin{abstract}
There is now compelling evidence of the effectiveness of a range of post-exercise recovery techniques, including extended nights of sleep, cold water immersion, massage, and compression garments. Currently, limited information is available on post-exercise recovery methods used by elite endurance athletes. Therefore, this study investigated the actual methods of recovery used in this group of athletes. Google Forms were used to collect information on the recovery methods used by elite endurance track and field athletes ( $n=153,61.4 \%$ men, 38.6\% women; average age: $22.7 \pm 4.6$ years). The most used methods of recovery were sauna bathing $(96.7 \%)$, massage $(86.9 \%)$, daytime nap (81.0\%), and long night sleep (at least 9h) (61.4\%). Recovery methods with proven effectiveness such as cold water immersion and compression garments were rarely used (15.0\% and $7.8 \%$, respectively). Overall, recovery methods were used more often when the tiers of the track and field athletes were higher. Massage and sauna bathing were the most used methods of post-exercise recovery among Russian endurance track and field athletes. In most cases, they were used in conjunction with short daytime nap and long night sleep. Higher tier athletes were more likely to use sauna bathing, massage, long night sleep, and daytime nap but not cold water immersion and compression garments as recovery methods; however, all these methods except for cold water immersion were widely used among elite-tier athletes.
\end{abstract}

Keywords: massage; sauna; recovery; elite endurance athletes

\section{Introduction}

Endurance athletes typically alternate periods of intense training with periods of rest and recovery to achieve peak performance. Inadequate recovery can disrupt the growth and regeneration of musculoskeletal tissues and lead to overuse injury [1]. During major tournaments, the incidence of trauma and illnesses can reach up to 235 per 1000 registered track and field athletes [2]. There is strong evidence supporting the association between the use of different post-exercise recovery methods and improvements in several markers of physical performance. Sleep optimization, massage, cold immersion, compression 
garments, and foam rollers have been shown to be effective for the recovery of athletes of various sports [3-9]. Effective recovery reduces injury rates and can improve performance; however, the development and implementation of effective methods of recovery is a challenge for experts working with track and field athletes.

One of the most common consequences of excessive training load is the development of delayed muscle soreness (DOMS), accompanied by a temporary decrease in muscle strength. For many athletes of different levels, it is probably the minimization of the severity and duration of DOMS that is the main subjective indicator of recovery. Athletes with DOMS who have to continue exercising daily are advised to reduce the intensity and duration of the exercises that cause discomfort while receiving treatment [10].

Many coaches believe that massage can provide several advantages, such as increased blood flow and reduced muscle and nervous strain. These methods can increase range of motion, elasticity, general relaxation, and reduce intensity of DOMS and anxiety. All these benefits provided by massage are believed to improve athletes' performance and reduce their risk of injury [3,4]. However, it is obvious that in addition to modifying the load in such situations, elite athletes also use other methods to minimize DOMS and recover as quickly as possible. However, here is little convincing evidence in support of the effectiveness of massage and sauna bathing despite their popularity.

In meta-analyses by Dupuy et al. [11] and Hohenauer et al. [12], data were obtained confirming the effectiveness of active recovery, massage, compression underwear, immersion in cold water, and contrast baths on the severity and duration of DOMS to varying degrees of severity. There are many more techniques used by athletes that can potentially accelerate post-exercise recovery.

Effectiveness of some methods is confirmed by data from studies of a high methodological level (meta-analyses and randomized controlled trials). However, there are methods with lack of scientific evidence of their effectiveness or contradictory data. The first group includes kinesiotaping, contrast baths, and acupuncture [13-18]. The second group of methods most likely includes cyclic compression therapy, stretching, general cryotherapy, and sauna use [19-24]. At the same time, there is little data on the actual prevalence of various recovery methods among elite athletes. It can only be assumed that they should most actively use post-exercise recovery methods with the most proven effectiveness.

Based on our observations, sauna bathing and massage have been mandatory requirements for training camps organized by coaches of Russian track and field athletes for many decades. It can be assumed that these methods are often used by this group of athletes. Considering the significant financial costs and technical difficulties necessary for its integration into the training process, a logical question arises about its appropriateness for use by professional athletes. In this study, we evaluated top-tier track and field endurance athletes, including the winners and medalists of national championships, world championships, and the Olympic Games. This cohort is among the most difficult for international researchers to gain access for research. The aim of this study was to analyze the use of various recovery methods, including massage and sauna bathing, in a group of elite endurance athletes.

We hypothesized that Russian endurance athletes incorporate sauna bathing and massage into their training regime often but follow protocols different from those previously described in published studies. We believe that such a study could help researchers to plan for future studies on the effect of sauna bathing and massage on post-exercise recovery based on the actual protocols used by young men and women athletes.

\section{Materials and Methods}

\subsection{Participants}

A total of 153 track and field Russian athletes who had performed or continue to perform at the top tier submitted their responses. All of them took part in national, continental, world championships, and the Olympic Games. Of the participants, $94(61.4 \%)$ of them were men, and $59(38.6 \%)$ of them were women (Table 1$)$. The questionnaire was submitted 
by athletes competing in racewalking and middle- and long-distance running (distances of $800-5000 \mathrm{~m}$ and 10,000 $\mathrm{m}$ or longer, respectively; Table 2). Overall, 80 athletes were nationallevel athletes, i.e., participants of national track and field championships (group "national level"), and 61 athletes had participated in major international tournaments, besides national championships (Olympic Games, World and European Championships) (group "international level"). Another 12 participants had received awards in major international competitions (group "extra tier") (Table 3).

Table 1. The questionnaire "Methods of recovery among highly competitive athletes training. Endurance".

\begin{tabular}{|ll|}
\hline Gender: & Age \\
\hline$\square$ men & Weight (kg) \\
$\square$ women & Height (cm) \\
\hline Main discipline: & Qualification: \\
$\square$ medium distances (800-5000 m) & $\square$ national level \\
$\square$ distance run (10,000 m and above) & $\square$ international level \\
$\square$ race walking & $\square$ winners of the European, World and \\
What recovery methods do you regularly use (have used): (Select all the options you use) \\
$\square$ massage & $\square$ active recovery \\
$\square$ bath/sauna & $\square$ cold baths \\
$\square$ long night sleep (at least 8 h of continuous & $\square$ compression underwear \\
sleep) & Other_ \\
$\square$ daytime sleep (30-60 min during the day) & \\
\hline Which of the recovery methods used above do you consider the most effective (name three in \\
descending order of effectiveness): \\
\hline
\end{tabular}

Table 2. Age, height, weight, and sex of athletes according to athletes in different sport disciplines.

\begin{tabular}{cccc}
\hline & Overall $(\boldsymbol{n = 1 5 3 )}$ & Men $(\boldsymbol{n}=\mathbf{9 4})$ & Women $(\boldsymbol{n}=\mathbf{5 9 )}$ \\
\hline Age (years) & $22.7 \pm 4.6$ & $22.5 \pm 4.9$ & $22.8 \pm 4.1$ \\
Weight $(\mathrm{kg})$ & $57.7 \pm 9.0$ & $61.9 \pm 8.6$ & $51.0 \pm 4.8$ \\
Height $(\mathrm{cm})$ & $171.9 \pm 8.3$ & $175.4 \pm 8.0$ & $166.3 \pm 5.1$ \\
Race walking, $n(\%)$ & $80(52.3)$ & Sport disciplines & $28(47.5)$ \\
Middle-distance, $n$ & $44(28.8)$ & $52(55.3)$ & $19(32.2)$ \\
$(\%)$ & $29(18.9)$ & $25(26.6)$ & $12(20.3)$ \\
Long distance, $n(\%)$ & $17(18.1)$ & \\
\hline
\end{tabular}

Table 3. Number of athletes of different tiers.

\begin{tabular}{cccc}
\hline & $\begin{array}{c}\text { National Tier } \\
\boldsymbol{n} \mathbf{( \% )}\end{array}$ & $\begin{array}{c}\text { International Tier } \\
\boldsymbol{n} \mathbf{( \% )}\end{array}$ & $\begin{array}{c}\text { Extra Tier } \\
\boldsymbol{n} \mathbf{( \% )}\end{array}$ \\
\hline Men & $57(60.6)$ & $31(33.0)$ & $6(6.4)$ \\
Women & $23(39.0)$ & $30(50.8)$ & $6(10.2)$ \\
Racewalking & $35(43.8)$ & $35(43.8)$ & $10(12.5)$ \\
Middle-distance & $27(61.4)$ & $16(36.4)$ & $1(2.3)$ \\
running & $18(62.1)$ & $10(34.5)$ & $1(3.4)$ \\
Long-distance & $80(52.3)$ & $61(39.9)$ & $12(7.8)$ \\
$\quad$ running & & &
\end{tabular}

\subsection{Inclusion and Exclusion Criteria \\ Inclusion criteria:}

$\checkmark$ written consent to participate in the study,

$\checkmark$ age 18 years and older, 
$\checkmark$ participation in the national athletics teams of Russia,

$\checkmark$ no previous disqualifications for anti-doping rule violation or disqualification.

Exclusion criteria:

$\checkmark$ currently taking medication,

$\checkmark$ psychosocial or emotional conditions,

$\checkmark$ any cardiovascular or ventilatory diseases during the last 2 years.

\subsection{Questionnaire}

In a pre-test, the questions and answer choices were presented to a group of $10 \mathrm{semi}-$ professional track and field athletes. Their answers were not considered in the analysis. To analyze the recovery methods used by highly competitive endurance athletes while preparing for important sporting events, the athletes were invited to complete an online questionnaire (Table 1) on their recovery methods, which was created using Google Forms. The questionnaire was made by authors and pretested on small cohort of amateur athletes. In relation to the two methods used (massage and sauna), additional questions were asked for the athletes who used them, the answers to which allowed us to determine the real protocols of their use in the studied group of athletes (Tables 4 and 5). Responses to the questionnaire were received between October 2020 and January 2021. We assessed the frequencies of use of various methods of recovery and their association with sex, age, sporting discipline, and tier. The most common combinations of different methods of recovery were also examined.

Table 4. The questionnaire "The Use of Massage as a Recovery Method Among Highly. Competitive Athletes Exercising Endurance in the Recovery of Athletes".

\begin{tabular}{|c|}
\hline $\begin{array}{l}\text { How long does the massage usually last? } \\
\square \text { up to } 10 \mathrm{~min} \\
\square \text { up to } 30 \mathrm{~min} \\
\square \text { up to } 60 \mathrm{~min} \\
\square \text { longer than } 60 \mathrm{~min}\end{array}$ \\
\hline $\begin{array}{l}\text { What type of massage have you used the most? } \\
\square \text { manual massage } \\
\square \text { self-massage } \\
\square \text { hardware massage }\end{array}$ \\
\hline $\begin{array}{l}\text { How often did you use massage when there was such an opportunity at training camps? } \\
\square 1-2 \text { times a week } \\
\square 3-4 \text { times a week } \\
\square \text { more often } 4 \text { times a week } \\
\square \text { less than once a week } \\
\text { Other }\end{array}$ \\
\hline $\begin{array}{l}\text { The most commonly used massage was: } \\
\text { (Multiple options can be selected) }\end{array}$ \\
\hline $\begin{array}{l}\square \text { immediately before the competition (less than } 24 \mathrm{~h} \text { ) } \\
\square \text { on the eve of the competition ( } 24-48 \mathrm{~h} \text { in advance) } \\
\square \text { immediately after the hardest workout (up to } 12 \mathrm{~h} \text { after the end) } \\
\square \text { the next day after the hardest workout ( } 12 \text { or more hours after the end) } \\
\text { Other }\end{array}$ \\
\hline
\end{tabular}


Table 5. The questionnaire "The use of sauna as a recovery method among highly. competitive athletes training endurance in the recovery of athletes".

\begin{tabular}{l}
\hline How often did you visit the bath/sauna, if there was such an opportunity at training camps? \\
$\square$ 1-2 times a week \\
$\square 3-4$ times a week \\
$\square$ more often 4 times a week \\
$\square$ less than once a week \\
$\square$ did not attend \\
Other \\
\hline What was the most frequent duration of the bath/sauna visit (total time spent in the steam \\
room): \\
$\square$ up to 10 min \\
$\square$ up to 30 min \\
$\square$ up to 60 min \\
$\square$ more than 60 min \\
\hline Most often the bath/sauna was visited \\
(Multiple options can be selected) \\
$\square$ immediately before the competition (less than $24 \mathrm{~h}$ ) \\
$\square$ on the eve of the competition (24-48 h in advance) \\
$\square$ immediately after the most difficult workout (up to $12 \mathrm{~h}$ after its end) \\
$\square$ the next day after the hardest workout (more than $12 \mathrm{~h}$ after its end) \\
Other
\end{tabular}

\subsection{Statistical Analysis}

The data were processed in Microsoft Excel and analyzed using GraphPad Prism 9(GraphPad Software, San Diego, CA, USA). Kolmogorov-Smirnov test was used to assess the normality of the distribution. To compare the frequencies of use of different recovery methods, chi-squared test and Fisher's F-test were used, and the odds ratio (OR) and 95\% confidence interval (CI) were calculated. To analyze the relationship between pairs of numerical values, Mann-Whitney U-test (or Student's t-test for normally distributed data) was used.

\section{Results}

The most used methods of recovery were sauna bathing (96.7\%), massage (86.9\%), daytime nap (81.0\%), and long night sleep (at least $9 \mathrm{~h})(61.4 \%)$. Interestingly, the frequencies of use of cold water immersion and compression garments were rather low $(15.0 \%$ and $7.8 \%$, respectively) despite their proven effectiveness. The frequencies of use of these methods of recovery did not differ between men and women athletes (Table 6, Figures 1-3).

Table 6. Frequency of use of various methods of recovery.

\begin{tabular}{|c|c|c|c|c|c|c|}
\hline & $\begin{array}{c}\text { Massage } \\
n(\%)\end{array}$ & $\begin{array}{c}\text { Sauna Bathing } \\
n(\%)\end{array}$ & $\begin{array}{c}\text { Daytime Nap } \\
n(\%)\end{array}$ & $\begin{array}{c}\text { Long Night } \\
\text { Sleep } \\
n(\%)\end{array}$ & $\begin{array}{l}\text { Compression } \\
\text { Garments } \\
n(\%)\end{array}$ & $\begin{array}{c}\text { Cold Water } \\
\text { Immersion } \\
n(\%)\end{array}$ \\
\hline Overall & $133(86.9)$ & $148(96.7)$ & $124(81.0)$ & $94(61,4)$ & $12(7.8)$ & $23(15.0)$ \\
\hline Men & $80(85.1)$ & $91(96.8)$ & $77(81.9)$ & $60(63.8)$ & $8(8.5)$ & $16(17.0)$ \\
\hline Women & $53(89.8)$ & $57(96.6)$ & $47(79.7)$ & $34(57.6)$ & $4(6.8)$ & $7(11.9)$ \\
\hline$p$ & 0.650 & 0.950 & 0.120 & 0.590 & 0.150 & 0.750 \\
\hline Racewalking & $71(88.8)$ & $77(96.3)$ & $75(93.8)$ & $52(65.0)$ & $3(3.8)$ & $7(8.8)$ \\
\hline Middle-distance running & $39(88.6)$ & $43(97.7)$ & $29(65.9)$ & $26(59.1)$ & $7(15.9)$ & $14(31.8)$ \\
\hline Long-distance running & $23(79.3)$ & $28(96.6)$ & $20(69.0)$ & $16(55.2)$ & $2(6.9)$ & $2(6.9)$ \\
\hline$p$ & 0.40 & 0.90 & $<0.001$ & 0.60 & $\mathrm{~N} / \mathrm{A}$ & $\mathrm{N} / \mathrm{A}$ \\
\hline National tier & $64(80.0)$ & $77(96.3)$ & $58(72.5)$ & $44(55.0)$ & $2(2.5)$ & $13(16.3)$ \\
\hline International tier & $57(93.4)$ & $59(96.7)$ & $56(91.8)$ & 39 (63.9) & $10(16.4)$ & $10(16.4)$ \\
\hline Elite tier & $12(100)$ & $12(100)$ & $10(83.3)$ & $11(91.7)$ & $12(100)$ & $0(0)$ \\
\hline$p$ & 0.024 & 0.790 & 0.015 & 0.046 & $\mathrm{~N} / \mathrm{A}$ & $\mathrm{N} / \mathrm{A}$ \\
\hline
\end{tabular}

N/A—not applicable, chi-square cannot be used because of limited observation amount. 


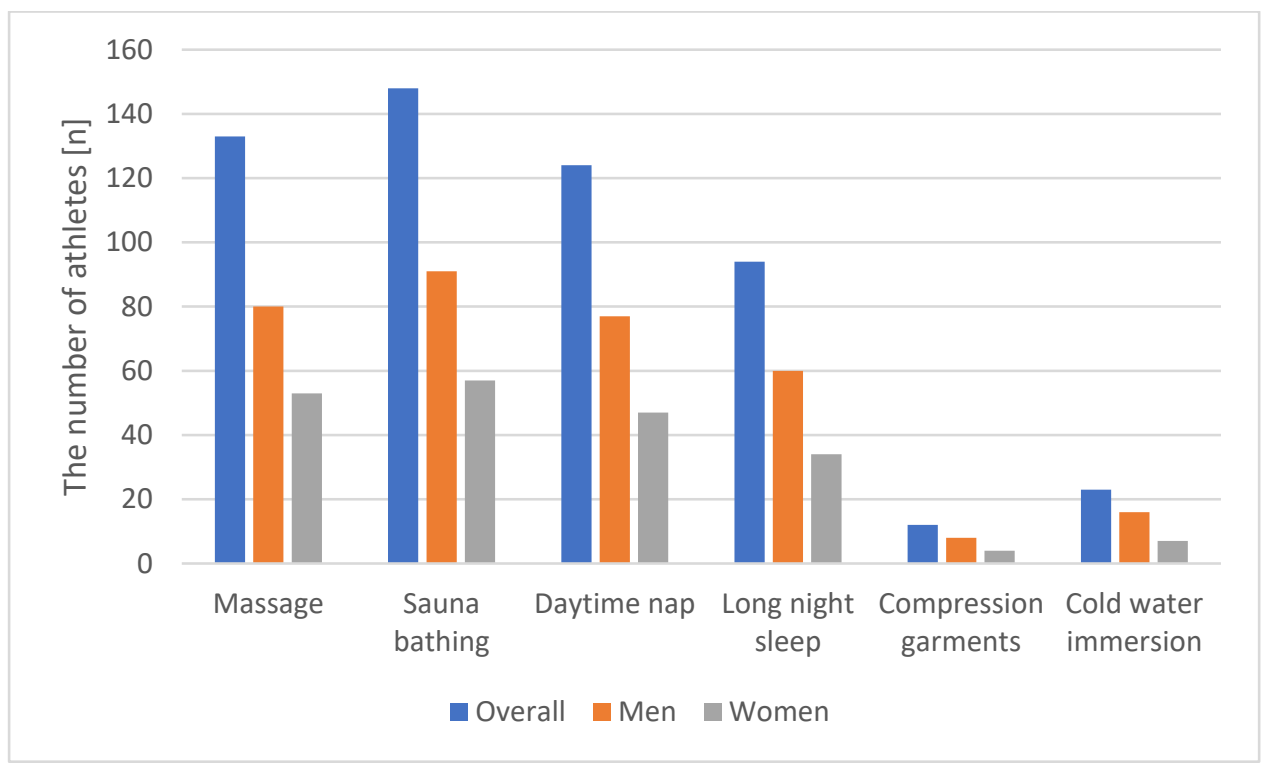

Figure 1. The use of recovery technique according to athletes' gender.

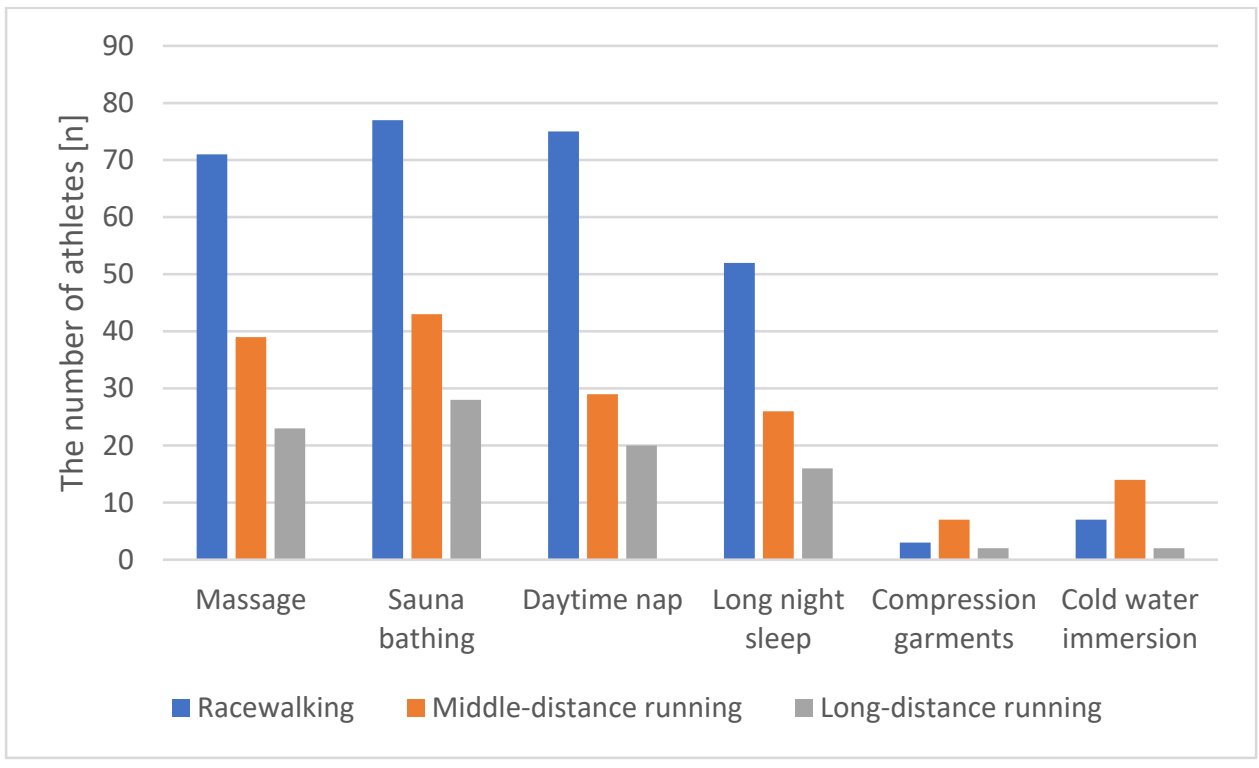

Figure 2. The use of recovery technique according to athletes' discipline.

\subsection{Massage}

The frequency of use of massage was significantly related to the tier of the athletes $(p=0.024)$. A pairwise comparison revealed that the frequency of massage use was significantly different between the national and international tier groups, which was more common among international athletes $(p=0.028$, $\mathrm{OR}=3.6,95 \% \mathrm{CI}=1.1-11.3)$. This method of recovery was used by all (100\%) elite-tier athletes (Table 6). Among all athletes of both sexes who used massage as a method of recovery, the most used technique was hand massage performed by a massage therapist for 30-60 min, at a frequency of 1-2 times a week or more than 4 times a week (Table 7). There was no significant difference between men and women in type of massage, session duration. Men used massage more than 4 times a week significantly more often than women, $p<0.001$, OR $=4.57,95 \%$ CI 2.07-10.1 (Table 6). 


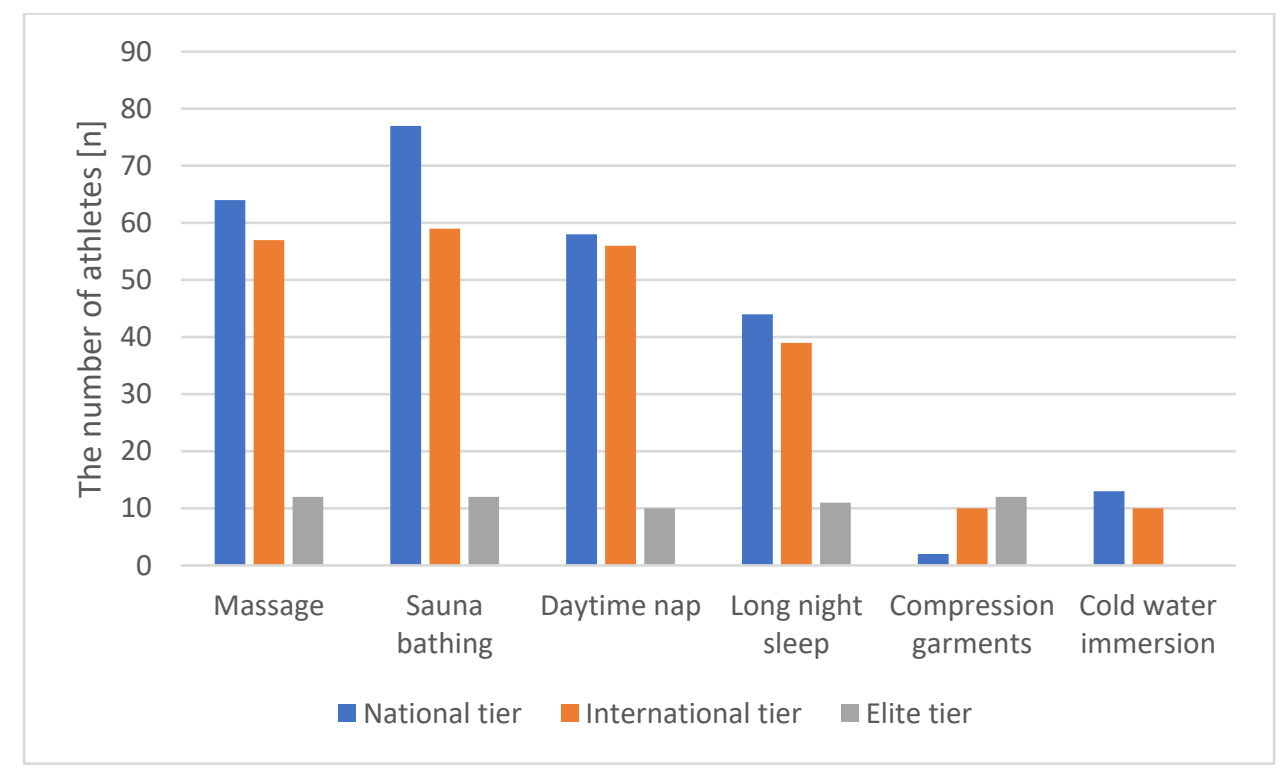

Figure 3. The use of recovery technique according to athletes' level.

Table 7. Massage: type, length, and frequency.

\begin{tabular}{ccccc}
\hline & $\begin{array}{c}\text { Men } \\
\boldsymbol{n} \mathbf{( \% )}\end{array}$ & $\begin{array}{c}\text { Women } \\
\boldsymbol{n} \mathbf{( \% )}\end{array}$ & $p$ & $\begin{array}{c}\text { Overall } \\
\boldsymbol{n} \mathbf{( \% )}\end{array}$ \\
\hline Type of massage & & & & \\
By hand & $75(93.8)$ & $52(98.1)$ & 0.24 & $127(95.5)$ \\
Machine & $2(2.5)$ & $0(0)$ & 0.25 & $2(1.5)$ \\
Self-massage & $3(3.8)$ & $1(1.9)$ & 0.54 & $4(3.0)$ \\
Session duration & & & & \\
Up to 10 min & $2(2.5)$ & $0(0)$ & 0.25 & $2(1,5)$ \\
Up to 30 min & $14(17.5)$ & $8(15.1)$ & 0.715 & $22(16.5)$ \\
Up to 60 min & $60(75.0)$ & $40(75.5)$ & 0.95 & $100(75.2)$ \\
Longer than 60 min & $4(5.0)$ & $5(9.4)$ & 0.32 & $9(6.8)$ \\
Frequency & & & & \\
Less than weekly & $6(7.5)$ & $3(5.7)$ & 0.68 & $9(6.8)$ \\
1-2 times a week & $22(27.5)$ & $23(43.4)$ & 0.06 & $45(33.8)$ \\
3-4 times a week & $11(13.8)$ & $8(15.1)$ & 0.83 & $19(14.3)$ \\
More than 4 times a week & $41(51.2)$ & $17(32.1)$ & $<0.001$ & $58(43.6)$ \\
\hline
\end{tabular}

\subsection{Sauna Bathing}

Most of the participants engaged in sauna bathing in 30-60-min sessions 1-2 times a week. There was no significant difference between men and women in frequency and duration of sauna (Tables 6 and 8).

\subsection{Daytime Nap}

The frequency of use of daytime nap as a method of recovery was associated with the sporting discipline $(p \leq 0.001)$ and athlete tier $(p=0.015)$. A pairwise comparison revealed that the frequency of use of daytime nap was significantly different between the national and international tier groups, which was more common among international athletes ( $p \leq 0.01, \mathrm{OR}=4.2,95 \% \mathrm{CI}=1.5-12.0)$. A statistically significant difference in the frequency of use of daytime nap was observed between athletes competing in racewalking and middle-distance running ( $p \leq 0.001, \mathrm{OR}=0.13,95 \% \mathrm{CI}=0.04-0.39)$ and between athletes competing in racewalking and long-distance running $(p \leq 0.001, \mathrm{OR}=0.15,95 \%$ CI 0.04-0.49), which was more common among racewalkers (Table 6). 
Table 8. Frequency and duration of sauna bathing.

\begin{tabular}{cccc}
\hline & $\begin{array}{c}\text { Men } \\
\boldsymbol{n} \mathbf{( \% )}\end{array}$ & $\begin{array}{c}\text { Women } \\
\boldsymbol{n} \mathbf{( \% )}\end{array}$ & $\begin{array}{c}\text { Overall } \\
\boldsymbol{n} \mathbf{( \% )}\end{array}$ \\
\hline Frequency & & & $143(96.6)$ \\
\hline 1-2 times a week & $87(956)$ & $56(98.2)$ & $5(3.4)$ \\
\hline 3-4 times a week & $4(4.4)$ & $1(1.8)$ & $6(4.1)$ \\
\hline Duration & & & $43(29.5)$ \\
\hline Up to 10 min & $5(5.6)$ & $17(29.8)$ & $62(42.2)$ \\
\hline Up to 30 min & $26(28.9)$ & $23(40.4)$ & $36(24.5)$ \\
\hline Up to 60 min & $39(43.3)$ & $16(28.1)$ &
\end{tabular}

\subsection{Long Night Sleep}

The frequency of use of long night sleep as a method of post-exercise recovery was significantly related to the tier of the athletes $(p \leq 0.05)$. A pairwise comparison revealed that the frequency of use of long night sleep was significantly different between the national and elite tier groups, which was significantly more common among elite-tier athletes $(p \leq 0.01$, OR $=11.3,95 \% \mathrm{CI}=1.3-95.2)$ (Table 6$)$.

\subsection{Compression Garments}

The frequency of use of compression garments as a method of post-exercise recovery was significantly related to the tier of the athletes $(p \leq 0.01)$. A pairwise comparison revealed that the frequency of use of compression garments was significantly different between the national and international tier groups, which was more common among international athletes $(p \leq 0.01, \mathrm{OR}=7.6,95 \% \mathrm{CI}=1.6-36.3)$. The use of compression sportswear was significantly associated with age $(p \leq 0.01)$, which was more common among older athletes according to the results of Mann-Whitney U test (Table 6).

\subsection{Cold Water Immersion}

The frequency of use of cold water immersion as a method of post-exercise recovery was significantly related to the sporting discipline $(p \leq 0.001)$. A pairwise comparison revealed that the frequency of use of cold water immersion was significantly different between athletes competing in racewalking and middle-distance running, which was more common among middle-distance runners ( $p \leq 0.001$, OR $=4.9,95 \% \mathrm{CI}=1.8-13.2$ ). The difference between athletes competing in middle- and long-distance running was also significant; the cold water immersion method was used more often by middle-distance runners $(p \leq 0.05, \mathrm{OR}=0.16,95 \% \mathrm{CI}=0.03-0.8)$.

\subsection{Combined Usage of Various Recovery Methods}

We examined the possible combinations of the recovery methods (cold immersion, massage, sauna bathing, daytime nap, long night sleep, and compression garments). Overall, 147 athletes used two or more methods of recovery (Table 9). The most common combinations were as follows:

(a) massage, sauna bathing, daytime nap, and long night sleep (38.6\%, combination 1$)$,

(b) massage, sauna bathing, and daytime nap (20.9\%, combination 2$)$,

(c) massage and sauna bathing $(7.8 \%$, combination 3$)$. 
Table 9. The number of athletes using different recovery strategies.

\begin{tabular}{cccc}
\hline Type of Athlete & Strategy 1 & Strategy 2 & Strategy 3 \\
\hline National tier & 17 & 9 & 23 \\
\hline International tier & 15 & 2 & 26 \\
\hline Elite tier & 0 & 1 & 10 \\
\hline Racewalking & 22 & 2 & 38 \\
\hline Middle-distance running & 6 & 6 & 11 \\
\hline Long-distance running & 4 & 4 & 10 \\
\hline
\end{tabular}

The rest of the combinations were used by seven or fewer people, therefore, only three indicated strategies were included in the further analysis. According to the Chi-square test, the use of one of these three strategies was not associated with gender $(p=0.21)$ and according to the Kruskal-Wallace test, the groups did not differ in age $(p=0.99)$. However, the use of one strategy or another was associated with the level of athletes $(p=0.029)$ and discipline $(p=0.025)$. In relation to sport discipline, athletes doing walking are significantly more likely to use strategy $1(p=0.005)$ and strategy $2(p=0.003)$ than athletes doing middle distances. A similar significance was revealed when comparing athletes doing walking versus staying running in relation to strategy $2(p=0.016)$ and strategy $1(p=0.009)$. International athletes are more likely to choose strategy $2(p=0.037)$ than national athletes. High level athletes more often choose strategy 2 than international $p=0.022$ ) and national $(p=0.012)$ athletes.

\section{Discussion}

Our findings demonstrated that sauna bathing, massage, daytime nap, and long night sleep were commonly used by Russian top-tier track and field endurance athletes as post-exercise recovery methods $(96.7 \%, 86.9 \%, 81 \%$, and $61.4 \%$, respectively). Massage and sauna bathing were frequently complemented by daytime nap and long night sleep. However, recovery methods with proven effectiveness such as cold water immersion and compression garments were rarely used (15\% and $7.8 \%$, respectively).

One of the main findings of our study was that the frequencies of use of various recovery methods were increased with the tier of the athletes. For instance, international athletes frequently used sauna bathing, massage, long night sleep, and daytime nap but not cold water immersion and compression garments as recovery methods; however, all these methods except for cold water immersion were widely used among elite-tier athletes. The use of compression garments was increased with the athlete age and tier despite its relative rarity.

The low frequency of use of cold water immersion and compression garments in our study may be attributed to the low awareness of athletes and coaches about their possible effectiveness. Compression garments are widely used by endurance athletes in other countries [25]. In a meta-analysis by Machado et al., diving in cold water for $60 \mathrm{~min}$ after the end of the exercise was also confirmed as a means of reducing the severity of DOMS (when compared with passive recovery) and it was concluded that there is a dose-response relationship. The most effective protocol for both rapid and delayed effects, according to the authors, is the use of water at a temperature of $11-15^{\circ} \mathrm{C}$ for $11-15 \mathrm{~min}$ [23]. Bleakley et al. also showed that cold water immersion can reduce delayed muscle soreness after exercise compared to passive interventions that include rest or no intervention [24].

In addition, several studies have provided evidence for the benefits of daytime nap, which is relevant to both 20-min naps before running and longer 40- and 90-min daytime naps $[26,27]$. The widespread use of daytime nap in the study group indicated its effectiveness, especially in the twice-a-day exercise regimen often used by endurance athletes while preparing for competitions. However, its effect on recovery rates requires further investigation. 
In the studies carried out, one of the most frequently used methods of restoration was massage, for which there is a sufficient amount of information about its effectiveness. Currently, there is insufficient information on the effectiveness of massage as a means of restoring and increasing physical performance. Several studies that reviewed the literature on the effectiveness of pre- and post-exercise massage have been published in recent years. Best et al. reviewed 27 studies (17 case series and 10 randomized controlled trials). The authors found some evidence of the benefits of using massage as a means of recovery from intense exercise [28]. A meta-analysis by Poppendieck et al. [29], which included 22 studies, also provided limited information on the effectiveness of both machine massage and massage by hand as methods of post-exercise recovery. According to their findings, the optimal duration of massage is $5-12 \mathrm{~min}$; the effectiveness of such a regimen is most evident in the immediate recovery period (up to $10 \mathrm{~min}$ ).

In 2020, a meta-analysis was published by Davis et al., which included 29 studies on pre- and post-exercise massage by hand. The authors also found no evidence supporting the theory that sports massage improves performance; however, it may improve flexibility and reduce DOMS [30]. Massage is still widely used by professional athletes despite the lack of evidence on its effectiveness. According to the available data, more than $70 \%$ of French and Spanish top-tier soccer teams use it for recovery [31]. It is also widely used as a recovery method in rugby, track and field athletics, and many other sports. More than $90 \%$ of top-tier Russian endurance athletes use massage by hand for recovery. These athletes consider it as one of the most effective recovery methods; the most common regimen is one or two 30-60-min sessions a week.

The discrepancy between the evidence showing the insufficient effectiveness of massage and its widespread use by professional athletes may be attributed to the difference between the protocols used in the studies and those used by the athletes. Thus far, all studies on the effect of massage on recovery only considered massage sessions that lasted for no more than $40 \mathrm{~min}$ (often less than that). In most cases, massage was performed once immediately following exercise. Our study showed that athletes mostly preferred massage by hand performed by a massage therapist in 30-60-min sessions, at a frequency of 1-2 times a week or more than 4 times a week. It should be noted that the vast majority of studies evaluated amateur athletes or only physically active people rather than professional athletes; this may also introduce bias to the results.

In contrast to massage, sleep, and cold water immersion, and the use of compression garments, there is currently no conclusive evidence on the effectiveness of sauna use as a post-exercise recovery method. Most studies involving athletes have shown that sauna bathing could effectively increase physical performance and heat acclimation in endurance athletes; however, there is no evidence to support its effectiveness as a method of postexercise recovery $[5,6]$. Sauna bathing has various physiological effects. There is ample evidence in support of the beneficial effects of regular sauna bathing on the cardiovascular, immune, and respiratory systems, as well as the lipid profile of individuals with various levels of physical activity $[7,8,32]$. Positive effects on the cardiovascular system may be associated with vascular dilation and reduction of arterial stiffness and blood pressure [33]. In comparison with wet sauna (low temperature and high humidity), dry sauna (high temperature and low humidity) is believed to be better tolerated by young men and women and induces a more gradual change in blood pressure. Most studies have analyzed the effects of dry sauna bathing [8,34]. However, there is no high-quality research on the effect of sauna bathing on the post-exercise recovery of top-tier endurance athletes.

Another common post-exercise recovery method among Russian track and field athletes was sauna bathing. Usually, it was used 1-2 times a week, and the most frequent durations were 30-60 min and more than $60 \mathrm{~min}$. In a few studies on the effect of sauna bathing on recovery, contradictory results were obtained; however, different protocols were used. Podstawski et al. noted that young, trained men exhibited a decrease in cortisol levels but not testosterone and prolactin levels after four 12-min sauna bathing sessions $\left(90-91^{\circ} \mathrm{C}\right.$, $14-16 \%$ relative humidity), interspersed by 1 -min sessions of cold water immersion [35]. 
However, a study by Scoon et al. [36] involving a cohort of long-distance runners showed that 30 -min sessions of sauna bathing for 3 weeks could lead to a $32 \%$ improvement in running time before exhaustion; this may be equivalent to a $1.9 \%$ improvement in race time. The outcome may be associated with a $7.1 \%$ increase in plasma volume and a $3.5 \%$ increase in red blood cell volume compared with those in the control group. On the other hand, Skorski et al. showed that three 8-min sessions of post-exercise sauna bathing at $80-85^{\circ} \mathrm{C}$ had a detrimental effect on the swimmers' times. The authors concluded that coaches should be mindful when choosing sauna bathing for post-exercise recovery [37].

A study published in 2020 involving 27 young men with prehypertension showed that sauna bathing immediately after endurance exercises was associated with improved blood pressure and increased plasma volume the following day [38]. Another study by the same authors showed that sauna bathing itself may be considered as a strenuous exercise that reduces the maximum load during isometric leg press and bench press and should not be recommended for at least $24 \mathrm{~h}$ before the next workout. At the same time, the study showed that sauna bathing immediately after exercise did not affect hormonal changes induced by various types of exercise [39].

Therefore, it can be hypothesized that an immediate positive effect on endurance associated with the increase in the plasma and red blood cell volume, rather than improved post-exercise recovery, may be the reason for the regular use of sauna bathing in the analyzed cohort. In specific situations, e.g., during preparation for events held under high temperature conditions, sauna bathing can also serve as a method of passive heat acclimation.

The limitations of this study include the cross-sectional nature of our work. In addition, some recovery methods, such as the consumption of certain products (proteins, branched chain amino acids, etc.) or the use of foam rollers, were not analyzed. Future studies should assess the effect of sauna bathing and massage, as well as their combination, on post-exercise recovery, speed, strength, and endurance according to the actual protocols used by top-tier athletes under various ambient conditions (different altitudes, humidity levels, temperatures, etc.).

\section{Conclusions}

Sauna bathing, massage, daytime nap, and long night sleep were widely used as methods of post-exercise recovery $(96.7 \%, 86.9 \%, 81.0 \%$, and $61.4 \%$, respectively). Massage and sauna bathing were the most used methods of post-exercise recovery among Russian endurance track and field athletes. In most cases, they were used in conjunction with daytime nap and long night sleep. Overall, recovery methods were used more often when the tiers of the track and field athletes were higher. International athletes frequently used sauna bathing, massage, long night sleep, and daytime nap but not cold water immersion and compression garments as recovery methods; however, all these methods except for cold water immersion were widely used among elite-tier athletes.

Author Contributions: Conceptualization, E.B..; methodology, E.B.; software, A.L.; validation, V.K. and A.L.; formal analysis, A.L.; investigation, A.L.; resources, E.B. and V.K.; data curation, E.B., A.L., V.K., S.C., A.T., O.T., D.G. and Z.W.; writing-original draft preparation, E.B., A.L., V.K., S.C., A.T., O.T., D.G. and Z.W.; writing-review and editing, E.B., A.L., V.K., S.C., A.T., O.T., D.G. and Z.W.; visualization, V.K.; supervision, V.K.; project administration, V.K. All authors have read and agreed to the published version of the manuscript.

Funding: This research received no external funding.

Institutional Review Board Statement: The study was approved by the Ethics Committee of Sechenov First National Medical University Local Ethical Committee in Moscow (22 Jan 2020; Ethics Approval Number: N 01-20).

Informed Consent Statement: Informed consent was obtained from all subjects involved in the study. 
Data Availability Statement: This statement if the study did not report any data.

Acknowledgments: The voluntarily participation of all athletes in the present study is gratefully acknowledged.

Conflicts of Interest: The authors declare no conflict of interest.

\section{References}

1. Cosca, D.D.; Navazio, F. Common problems in endurance athletes. Am. Fam. Physician 2007, 76, $237-244$.

2. Edouard, P.; Navarro, L.; Branco, P.; Gremeaux, V.; Timpka, T.; Junge, A. Injury frequency and characteristics (location, type, cause and severity) differed significantly among athletics ('track and field') disciplines during 14 international championships (2007-2018): Implications for medical service planning. Br. J. Sports Med. 2020, 54, 159-167. [CrossRef]

3. Moraska, A. Sports massage: A comprehensive review. J. Sports Med. Phys. Fitness 2005, 45, 370-380. [PubMed]

4. Weerapong, P.; Hume, P.A.; Kolt, G.S. The mechanisms of massage and effects on performance, muscle recovery and injury prevention. Sport. Med. 2005, 35, 235-256. [CrossRef]

5. Heathcote, S.L.; Hassmén, P.; Zhou, S.; Stevens, C.J. Passive heating: Reviewing practical heat acclimation strategies for endurance athletes. Front. Physiol. 2018, 9, 1851. [CrossRef]

6. $\quad$ Kirby, N.V.; Lucas, S.J.E.; Armstrong, O.J.; Weaver, S.R.; Lucas, R.A.I. Intermittent post-exercise sauna bathing improves markers of exercise capacity in hot and temperate conditions in trained middle-distance runners. Eur. J. Appl. Physiol. 2021, 121, 621-635. [CrossRef]

7. Pilch, W.; Pokora, I.; Szygulła, Z.; Palłka, T.; Pilch, P.; Cisoń, T.; Malik, L.; Wiecha, S. Effect of a single finnish sauna session on white blood cell profile and cortisol levels in athletes and non-athletes. J. Hum. Kinet. 2013, 39, 127. [CrossRef]

8. Henderson, K.N.; Killen, L.G.; O'neal, E.K.; Waldman, H.S. The cardiometabolic health benefits of sauna exposure in individuals with high-stress occupations. A mechanistic review. Int. J. Environ. Res. Public Health 2021, 18, 1105. [CrossRef] [PubMed]

9. Hill, J.; Howatson, G.; van Someren, K.; Leeder, J.; Pedlar, C. Compression garments and recovery from exercise-induced muscle damage: A meta-analysis. Br. J. Sports Med. 2014, 48, 1340-1346. [CrossRef]

10. Cheung, K.; Hume, P.A.; Maxwell, L. Delayed onset muscle soreness: Treatment strategies and performance factors. Sport. Med. 2003, 33, 145-164. [CrossRef]

11. Dupuy, O.; Douzi, W.; Theurot, D.; Bosquet, L.; Dugué, B. An evidence-based approach for choosing post-exercise recovery techniques to reduce markers of muscle damage, Soreness, fatigue, and inflammation: A systematic review with meta-analysis. Front. Physiol. 2018, 9, 403. [CrossRef]

12. Hohenauer, E.; Taeymans, J.; Baeyens, J.P.; Clarys, P.; Clijsen, R. The effect of post-exercise cryotherapy on recovery characteristics: A systematic review and meta-analysis. PLoS ONE 2015, 10, e0139028. [CrossRef] [PubMed]

13. Lin, J.; Guo, M.L.; Wang, H.; Lin, C.; Xu, G.; Chen, A.; Chen, S.; Wang, S. Effects of Kinesio Tape on Delayed Onset Muscle Soreness: A Systematic Review and Meta-analysis. BioMed Res. Int. 2021, 2021, 6692828. [CrossRef] [PubMed]

14. Kirmizigil, B.; Chauchat, J.R.; Yalciner, O.; Iyigun, G.; Angin, E.; Baltaci, G. The effectiveness of kinesio taping in recovering from delayed onset muscle soreness: A crossover study. J. Sport Rehabil. 2020, 29, 385-393. [CrossRef] [PubMed]

15. Huang, C.; Wang, Z.; Xu, X.; Hu, S.; Zhu, R.; Chen, X. Does Acupuncture Benefit Delayed-Onset Muscle Soreness After Strenuous Exercise? A Systematic Review and Meta-Analysis. Front. Physiol. 2020, 11, 666. [CrossRef] [PubMed]

16. Ko, G.W.Y.; Clarkson, C. The effectiveness of acupuncture for pain reduction in delayed-onset muscle soreness: A systematic review. Acupunct. Med. 2020, 38, 63-74. [CrossRef]

17. Cardoso, R.; Lumini-Oliveira, J.A.; Santos, M.J.; Ramos, B.; Matos, L.C.; Machado, J.; Greten, H.J.; Franconi, G. Acupuncture can be beneficial for exercise-induced muscle soreness: A randomised controlled trial. J. Bodyw. Mov. Ther. 2020, 24, 8-14. [CrossRef]

18. Wang, Y.; Li, S.; Zhang, Y.; Chen, Y.; Yan, F.; Han, L.; Ma, Y. Heat and cold therapy reduce pain in patients with delayed onset muscle soreness: A systematic review and meta-analysis of 32 randomized controlled trials. Phys. Ther. Sport 2021, 48, 177-187. [CrossRef] [PubMed]

19. Afonso, J.; Clemente, F.M.; Nakamura, F.Y.; Morouço, P.; Sarmento, H.; Inman, R.A.; Ramirez-Campillo, R. The Effectiveness of Post-exercise Stretching in Short-Term and Delayed Recovery of Strength, Range of Motion and Delayed Onset Muscle Soreness: A Systematic Review and Meta-Analysis of Randomized Controlled Trials. Front. Physiol. 2021, 12, 553. [CrossRef] [PubMed]

20. Costello, J.T.; Baker, P.R.A.; Minett, G.M.; Bieuzen, F.; Stewart, I.B.; Bleakley, C. Whole-body cryotherapy (extreme cold air exposure) for preventing and treating muscle soreness after exercise in adults. Cochrane Database Syst. Rev. 2015, 18, CD010789. [CrossRef]

21. Draper, S.N.; Kullman, E.L.; Sparks, K.E.; Little, K.; Thoman, J. Effects of intermittent pneumatic compression on delayed onset muscle soreness (DOMS) in long distance runners. Int. J. Exerc. Sci. 2020, 13, 75. [PubMed]

22. Heiss, R.; Hotfiel, T.; Kellermann, M.; May, M.S.; Wuest, W.; Janka, R.; Nagel, A.M.; Uder, M.; Hammon, M. Effect of compression garments on the development of edema and soreness in delayed-onset muscle soreness (DOMS). J. Sport. Sci. Med. 2018, 17, 392.

23. Machado, A.F.; Ferreira, P.H.; Micheletti, J.K.; de Almeida, A.C.; Lemes, Í.R.; Vanderlei, F.M.; Netto Junior, J.; Pastre, C.M. Can Water Temperature and Immersion Time Influence the Effect of Cold Water Immersion on Muscle Soreness? A Systematic Review and Meta-Analysis. Sport. Med. 2016, 46, 503-514. [CrossRef] 
24. Bleakley, C.; McDonough, S.; Gardner, E.; Baxter, D.G.; Hopkins, T.J.; Davison, G.W. Cold-water immersion (cryotherapy) for preventing and treating muscle soreness after exercise. Sao Paulo Med. J. 2012, 2012, CD008262. [CrossRef]

25. Franke, T.P.C.; Backx, F.J.G.; Huisstede, B.M.A. Lower extremity compression garments use by athletes: Why, how often, and perceived benefit. BMC Sports Sci. Med. Rehabil. 2021, 13, 31. [CrossRef] [PubMed]

26. Blanchfield, A.W.; Lewis-Jones, T.M.; Wignall, J.R.; Roberts, J.B.; Oliver, S.J. The influence of an afternoon nap on the endurance performance of trained runners. Eur. J. Sport Sci. 2018, 18, 1177-1184. [CrossRef] [PubMed]

27. Boukhris, O.; Trabelsi, K.; Ammar, A.; Abdessalem, R.; Hsouna, H.; Glenn, J.M.; Bott, N.; Driss, T.; Souissi, N.; Hammouda, O.; et al. A 90 min daytime nap opportunity is better than $40 \mathrm{~min}$ for cognitive and physical performance. Int. J. Environ. Res. Public Health 2020, 17, 4650. [CrossRef]

28. Best, T.M.; Hunter, R.; Wilcox, A.; Haq, F. Effectiveness of sports massage for recovery of skeletal muscle from strenuous exercise. Clin. J. Sport Med. 2008, 18, 446-460. [CrossRef]

29. Poppendieck, W.; Wegmann, M.; Ferrauti, A.; Kellmann, M.; Pfeiffer, M.; Meyer, T. Massage and Performance Recovery: A Meta-Analytical Review. Sport. Med. 2016, 46, 183-204. [CrossRef]

30. Davis, H.L.; Alabed, S.; Chico, T.J.A. Effect of sports massage on performance and recovery: A systematic review and metaanalysis. BMJ Open Sport Exerc. Med. 2020, 6, e000614. [CrossRef]

31. Altarriba-Bartes, A.; Peña, J.; Vicens-Bordas, J.; Casals, M.; Peirau, X.; Calleja-González, J. The use of recovery strategies by Spanish first division soccer teams: A cross-sectional survey. Phys. Sportsmed. 2021, 49, 297-307. [CrossRef]

32. Kunutsor, S.K.; Laukkanen, T.; Laukkanen, J.A. Sauna bathing reduces the risk of respiratory diseases: A long-term prospective cohort study. Eur. J. Epidemiol. 2017, 32, 1107-1111. [CrossRef] [PubMed]

33. Laukkanen, J.A.; Laukkanen, T.; Kunutsor, S.K. Cardiovascular and Other Health Benefits of Sauna Bathing: A Review of the Evidence. Mayo Clin. Proc. 2018, 93, 1111-1121. [CrossRef] [PubMed]

34. Pilch, W.; Szygula, Z.; Palka, T.; Pilch, P.; Cison, T.; Wiecha, S.; Tota, L. Comparison of physiological reactions and physiological strain in healthy men under heat stress in dry and steam heat saunas. Biol. Sport 2014, 31, 145. [CrossRef]

35. Podstawski, R.; Borysławski, K.; Pomianowski, A.; Krystkiewicz, W.; Żurek, P. Endocrine Effects of Repeated Hot Thermal Stress and Cold Water Immersion in Young Adult Men. Am. J. Mens. Health 2021, 15, 15579883211008339. [CrossRef] [PubMed]

36. Scoon, G.S.M.; Hopkins, W.G.; Mayhew, S.; Cotter, J.D. Effect of post-exercise sauna bathing on the endurance performance of competitive male runners. J. Sci. Med. Sport 2007, 10, 259-262. [CrossRef] [PubMed]

37. Skorski, S.; Schimpchen, J.; Pfeiffer, M.; Ferrauti, A.; Kellmann, M.; Meyer, T. Effects of postexercise sauna bathing on recovery of swim performance. Int. J. Sports Physiol. Perform. 2020, 15, 934-940. [CrossRef] [PubMed]

38. Rissanen, J.A.; Häkkinen, K.; Laukkanen, J.A.; Häkkinen, A. Acute Hemodynamic Responses to Combined Exercise and Sauna. Int. J. Sports Med. 2020, 41, 824-831. [CrossRef] [PubMed]

39. Rissanen, J.A.; Häkkinen, A.; Laukkanen, J.; Kraemer, W.J.; Häkkinen, K. Acute Neuromuscular and Hormonal Responses to Different Exercise Loadings Followed by a Sauna. J. Strength Cond. Res. 2020, 34, 313-322. [CrossRef] 